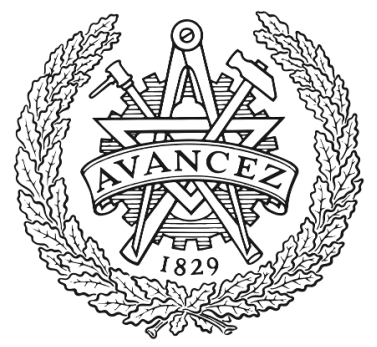

CHALMERS

UNIVERSITY OF TECHNOLOGY

\title{
A dual-polarized slotted-waveguide antenna based on gap waveguide technology
}

Downloaded from: https://research.chalmers.se, 2023-04-26 12:11 UTC

Citation for the original published paper (version of record):

Ferrando-Rocher, M., Uz Zaman, A., Yang, J. et al (2017). A dual-polarized slotted-waveguide antenna based on gap waveguide technology. 2017 11th European Conference on Antennas and Propagation, EUCAP 2017: 3726-3727. http://dx.doi.org/10.23919/EuCAP.2017.7928442

N.B. When citing this work, cite the original published paper. 


\title{
A Dual-Polarized Slotted-Waveguide Antenna Based on Gap Waveguide Technology
}

\author{
Miguel Ferrando-Rocher ${ }^{1}$, A. U. Zaman ${ }^{2}$, Jian Yang ${ }^{2}$, Alejandro Valero-Nogueira ${ }^{1}$ \\ ${ }_{1}^{1}$ Team Institute. Universitat Politècnica de València, Valencia, Spain \\ ${ }^{2}$ Chalmers University of Technology, Gothenburg, Sweden
}

\begin{abstract}
This paper describes a wide-band dual-polarized slotted-waveguide antenna working at V-band $(57$ - $66 \mathrm{GHz})$ based on Gap Waveguide concept. The antenna has three layers. The first one (feeding-layer 1) is practically identical to the second one (feeding-layer 2). This optimizes the design and facilitates manufacturing. The corporate-feeding networks on the two layers are rotated 90 degrees to each other to get the two orthogonal polarizations. Radiating elements are square apertures located on the top of the antenna. Simulated results show both impedance bandwidth and radiation pattern bandwidth greater than $15 \%$ for both polarizations.
\end{abstract}

Index Terms-Dual-polarization, Slotted-Waveguide, Gap Waveguides.

\section{INTRODUCTION}

Many radar and communication systems use two polarizations to increase capacity by reusing the available spectrum. In dual polarization systems it is possible to reuse the area of the aperture for the two beams simultaneously. Most of the studies on the dual-polarized array antennas use microstrip patches and lines because of the easy realization of the radiating elements and the feeding networks. It is a hottopic of growing interest and there are several publications that have proposed dual-polarized antennas using multilayer feeding [1], [2]. These solutions are valid in the frequency bands where the feed network losses are not critical. From the $\mathrm{Ka}$ band and above it is necessary to explore new low-loss corporate-feed networks or beam-forming networks for dualpolarized antennas. From the authors knowledge, there are only a few previous publications on dual-polarization slottedwaveguide array antenna beyond Ka-band. In most previous works, the sub-arrays with orthogonal linear polarizations are placed alternately which leads to have a relatively large distance between the radiating slots [3]. A solution with crossshaped radiating slots at V-band can be found in [4]. This antenna is fabricated by the diffusion bonding of laminated thin metal plates and has the advantages of high-precision and low-loss characteristics. The main problem of this antenna is that diffusion bonding is, at the moment, an expensive technique. In this paper a multilayer feeding solution based on Gap waveguide (GW) [5] is proposed, which has the advantage of low loss and ease of assembly since the electrical contact is avoided in gap waveguide structures. The two orthogonal linear polarizations are excited at the same time in the radiating part, composed of square apertures.

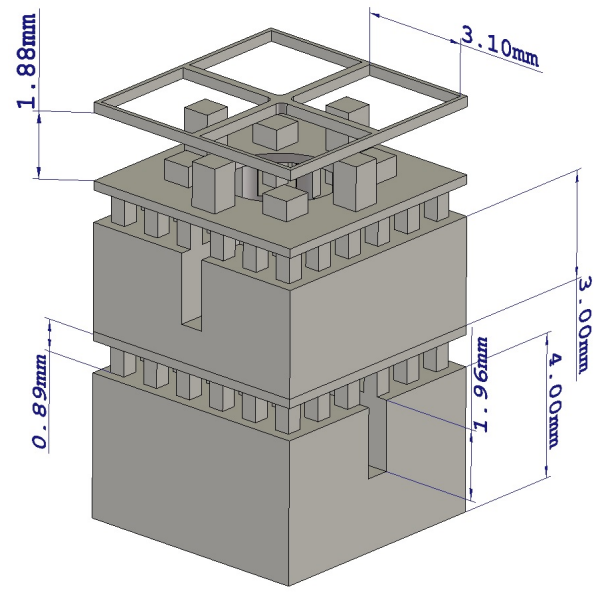

Fig. 1. Feeding layer of the single-layer slot antenna using RGR transitions

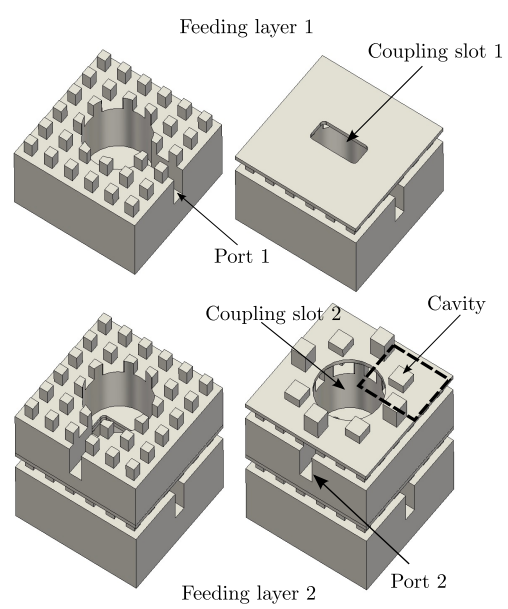

Fig. 2. Feeding layer of the single-layer slot antenna using RGR transitions

\section{II. $2 \times 2$ DUAL-POLARIZED ARRAY DESIGN}

A $2 \times 2$ array is designed as a unit cell. The cell unit is fed by two groove gap waveguides. The coupling between the feeding-layer 1 and the feeding-layer 2 is via a longitudinal slot. The radiating layer is composed of 4 square apertures that radiate uniformly for both polarizations. This unit cell could easily be extended to a larger array according to Fig. 3 using E-plane power dividers and splitters in Gap Waveguide. 


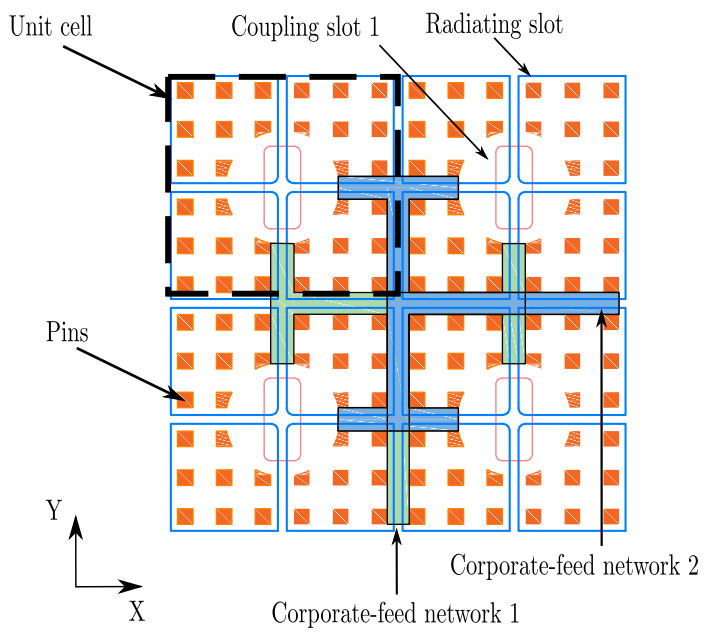

Fig. 3. Corporate feed-network of $4 \times 4$ slots to excite both longitudinal and transverse components

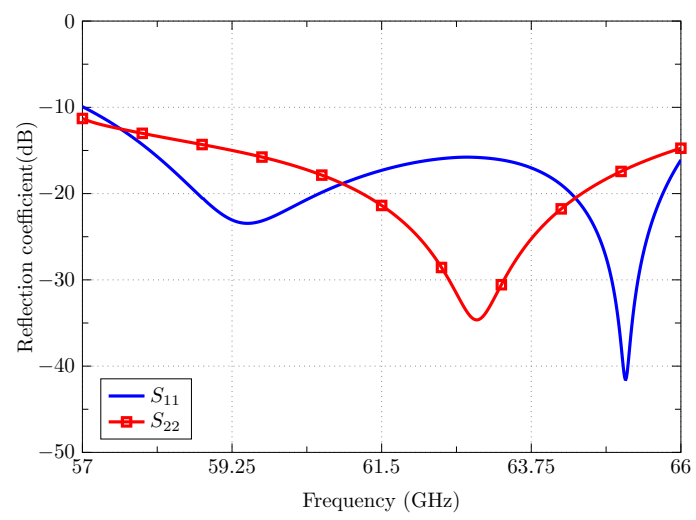

Fig. 4. Simulated reflection coefficients

\section{A. Simulated results}

Fig. 4 shows the simulated reflection coefficient of the $2 \times 2$ dual-polarized array antenna. Whole band is covered for both polarizations for a $S_{11}<-10 \mathrm{~dB}$. The isolation between the 2 ports is better than $55 \mathrm{~dB}$ over the bandwidth. Radiation patterns are simulated at the center frequency $(61.5 \mathrm{GHz})$ in both E- and H-planes for both $\mathrm{x}$ - and y-direction polarization (Figs. 5 and 6) featuring a well-defined beam in the broadside direction and SLL less than $13 \mathrm{~dB}$.

\section{CONCLUSIONS}

A dual-polarized slotted-waveguide antenna based on Gap Waveguide technology is designed for V-band. The work presented in this paper concentrates on a unit cell with $2 \times 2$ radiating slots which is easily expandable to a bigger antenna. The results of this unit cell are promising since the impedance bandwidth is greater than $15 \%$ and a symmetric radiation pattern have been obtained for both polarizations.

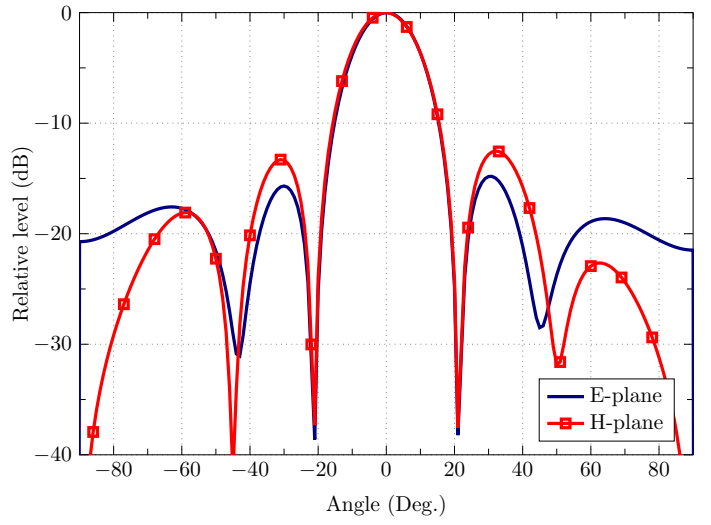

Fig. 5. x-direction polarization

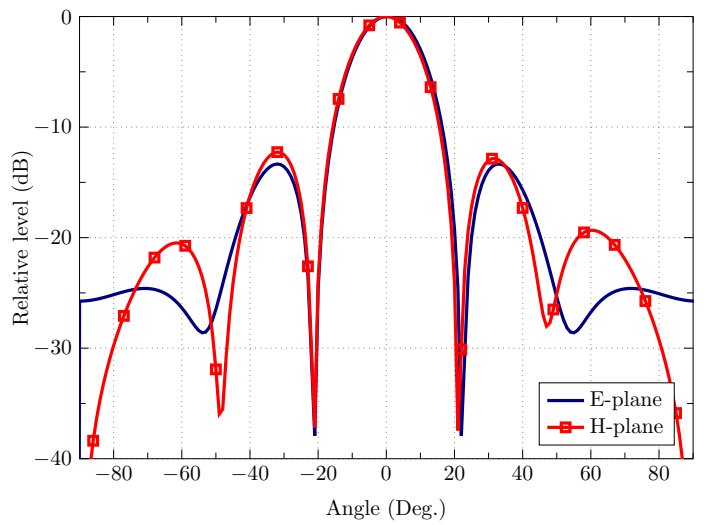

Fig. 6. y-direction polarization

\section{ACKNOWLEDGEMENTS}

This work was supported by the Spanish Ministerio de Economia y Competitividad under Project TEC2013-47360C3-3-P and the fellowship BES-2014-067917.

\section{REFERENCES}

[1] S.-C. Gao, L.-W. Li, M.-S. Leong, and T.-S. Yeo, "Dual-polarized slotcoupled planar antenna with wide bandwidth," IEEE Transactions on Antennas and Propagation, vol. 51, no. 3, pp. 441-448, March 2003.

[2] S. K. Padhi, N. C. Karmakar, C. L. Law, and S. Aditya, "A dual polarized aperture coupled circular patch antenna using a c-shaped coupling slot," IEEE Transactions on Antennas and Propagation, vol. 51, no. 12, pp. 3295-3298, Dec 2003.

[3] S. Park, Y. Okajima, J. Hirokawa, and M. Ando, "A slotted post-wall waveguide array with interdigital structure for $45 \mathrm{deg}$; linear and dual polarization," IEEE Transactions on Antennas and Propagation, vol. 53 , no. 9, pp. 2865-2871, Sept 2005.

[4] D. Kim, M. Zhang, J. Hirokawa, and M. Ando, "Design and fabrication of a dual-polarization waveguide slot array antenna with high isolation and high antenna efficiency for the $60 \mathrm{ghz}$ band," IEEE Transactions on Antennas and Propagation, vol. 62, no. 6, pp. 3019-3027, June 2014.

[5] P. S. Kildal, E. Alfonso, A. Valero-Nogueira, and E. Rajo-Iglesias, "Local metamaterial-based waveguides in gaps between parallel metal plates," IEEE Antennas and Wireless Propagation Letters, vol. 8, pp. 84-87, 2009. 